\title{
Instagram e educação: a aprendizagem significativa de língua estrangeira em contextos não-formais de ensino
}

\author{
Carolina Morais R. Silva ${ }^{1}$, José Aires de Castro Filho ${ }^{1}$, Raquel Santiago Freire ${ }^{2}$ \\ ${ }^{1}$ Programa de Pós-Graduação em Educação- Universidade Federal do Ceará (UFC) \\ Rua Waldery Uchoa, 01- Benfica, 60020-110- Fortaleza, CE- Brazil \\ ${ }^{2}$ Instituto UFC Virtual - Universidade Federal do Ceará (UFC) \\ Fortaleza-CE - Brasil \\ carolina.morais, aires, freire \{evirtual.ufc.br\}
}

\begin{abstract}
This paper aims to describe an experience of using Instagram application by a free language course teacher from Fortaleza (Ce), in Brazil. Through the description of the activities carried out with a group of students, we verified the multiple possibilities of using the available tools in the application for the use of oral and written comprehension practices, offering input to promote interaction between students and their immersion in the target language and its culture.
\end{abstract}

Resumo. Este artigo tem por objetivo descrever uma experiência de uso do aplicativo Instagram por uma professora de curso livre de linguas de Fortaleza (Ce), no Brasil. Através da descrição das atividades realizadas com um grupo de alunos, foram verificadas as múltiplas possibilidades de uso das ferramentas disponíveis no aplicativo para o emprego de práticas de compreensão oral e escrita, oferecendo insumo para promoção da interação entre alunos e imersão na língua-alvo e sua cultura.

\section{Introdução}

A prática das habilidades (essenciais) para a aprendizagem de uma língua estrangeira em salas de ensino de língua inglesa, no Brasil, tem encontrado obstáculos para sua realização. Dentre os problemas, podemos destacar, a desmotivação dos alunos [HARNETT, 2014] e a falta de meios de se trabalhar o caráter global da língua [TANGI; GARCIA, 2009] como os problemas que mais afetam os professores, principalmente no que concerne o trabalho com a oralidade em língua estrangeira (doravante LE) em sala de aula, o qual deve ser estruturado conforme a competência comunicativa do falante.

A competência comunicativa é composta por três tipos de conhecimentos distintos, apontados pelos Parâmetros Curriculares Nacionais de Língua Estrangeira (PCN). Estando classificados em conhecimento de organização textual, conhecimento de mundo e conhecimento sistêmico [BRASIL, 1998], estes conhecimentos são importantes para um aprendiz de inglês - língua estrangeira e devem ser trabalhados em sala de aula. O problema é como trabalhar os conhecimentos que constituem a competência comunicativa de um aprendiz de inglês, de forma significativa, ampliando a experiência desse aprendiz para além-classe. Além disso, perguntamo-nos como fazer para estreitarmos os vínculos professor-aluno, alunos-alunos e fazer com que a turma 
VII Congresso Brasileiro de Informática na Educação (CBIE 2018)

Anais dos Workshops do VII Congresso Brasileiro de Informática na Educação (WCBIE 2018)

associe os conteúdos trabalhados em sala de aula de maneira mais natural, tendo acesso aos conteúdos de forma autônoma.

Com intuito de responder esses questionamentos e com base em uma literatura que discorre sobre as tecnologias de informação e comunicação (TIC) na educação [ARISTOVNIK 2012; KATTIMANI; NAIK, 2012; RUBIO; ROMERO, 2005], uma conta no software aplicativo Instagram foi criada, sob o perfil intitulado @a_teacher_carol, com o objetivo de promover a aprendizagem dos alunos através de metodologias gamificadas [BRITO; MADEIRA, 2017]. As metodologias gamificadas, também chamadas por seu termo em inglês, gamification, surgiram da necessidade em se reverter o quadro da desmotivação estudantil, utilizando-se de elementos e técnicas de jogos digitais para promover maior engajamento dos estudantes em sala de aula. A ideia do uso do aplicativo Instagram para fins educacionais nasceu da observação da professora, a partir da ampla e constante utilização do aplicativo por seus alunos, principalmente no que concerne à cultura maker [BLIKSTEIN, 2013; RAABE, 2016], em que o usuário utiliza canais de comunicação para aprender como fazer coisas, seguindo perfis de tutoriais ou "DIY"1, em que maquiagens, artesanatos e até mesmo reparos em casa (bricolagem) são ensinados.

O conceito do aluno ou do professor ser maker ou criar seus resultados, sendo um resultado físico ou não, faz parte da teoria construcionista [DEWEY, 2001, 2010; PAPERT, 1986, 1991, 2007], corroborando com a ideia de um maior protagonismo da aprendizagem, em que o estudante e o professor constroem, por exemplo, seu vocabulário e a sua aplicação, de acordo com a sua necessidade. Encontrando um propósito para seu uso, a aprendizagem de novas formas gramaticais, da pronúncia de termos ou expressões ou da aplicação de conectivos, por exemplo, passa a ser uma aprendizagem carregada de significados, uma vez que o aprendiz compreende a necessidade de aplicação do insumo oferecido pelo professor. A cultura maker, ou a cultura dos "fazedores" consiste em criar, construir e compartilhar. O professor, ao observar quais são as necessidades de seus alunos, tem autonomia de construir materiais específicos e compartilhá-los, personalizando-os de acordo com o contexto em que se situa. O professor também ganha com essa construção e aprende em sua prática pedagógica.

Tendo em vista uma forma mais eficaz de se promover a prática oral fora de sala de aula, ampliando seus contextos, e com intuito de que a aprendizagem ocorra de forma significativa para os alunos, é necessário que se pense em ferramentas que possuam amplas possibilidades de uso, tornando versáteis seus contextos de aprendizagem. Citamos, então, o seu potencial pedagógico. De acordo com Pivelli [2006, p. 74], potencial pedagógico pode ser definido como "o produto da somatória dos recursos visuais, auditivos, tácteis, olfativos e gustativos (potencial expositivo) presentes nos locais estudados mais as propostas pedagógicas institucionais que envolvem estes recursos". O que desejamos é propor um contexto de aplicação que fuja dos moldes formais [SIMSOM et al, 2001; SMITH, 1996], em que os conteúdos sejam aplicados em contextos não-formais [GOHN,1999] de ensino, como é o caso do Instagram, em que o aluno pode acessar de qualquer lugar, sem que isso seja uma atividade obrigatória. $\mathrm{O}$ aluno acessa o conteúdo e esta atividade possui conexão com as atividades planejadas para a sala de aula.

\footnotetext{
${ }^{1}$ Do inglês, “do it yourself", aqui traduzido livremente por "faça você mesmo".
} 
O perfil foi criado com o intuito de, assumindo uma postura maker do professor e construcionista para suas aulas, realizar, de forma dinâmica, ações e tarefas antes feitas em sala de aula de forma não-significativa. Exercícios tradicionais foram transformados em exercícios gamificados, utilizando este software-aplicativo familiar aos alunos, tendo como principal resultado o alcance dos resultados, nos quais os conteúdos foram trabalhados além da sala de aula, alcançando público além dos alunos.

Esta pesquisa reflete também o impacto causado nas novas formas de se utilizar este aplicativo, originalmente criado para fins de entretenimento. Afinal, até onde vamos dicotomizar as noções de aprendizado e de entretenimento? Porque o aprendizado não pode andar lado a lado com o que é ofertado para o lazer, trazendo, como consequência, a aprendizagem? Desta forma, este trabalho tem como objetivo trazer reflexão de como aliar as TIC como insumo curricular através do aplicativo Instagram. Na seção seguinte, serão apresentados os procedimentos e estratégias, bem como os sujeitos participantes e a metodologia de coleta e análise de dados.

\section{Metodologia}

Este estudo define-se como uma pesquisa-ação educacional, pois teve uma "a ação planejada, de uma intervenção com mudanças dentro da situação investigada". [THIOLLENT, 1999, p. 83-84]. Sendo sua abordagem de natureza qualitativa, permitindo ao pesquisador dedicar-se a um universo que abriga significados, aspirações, motivos, crenças, atitudes e valores, correspondendo à acomodação de processos e fenômenos que não podem ser reduzidos à instrumentalização de variáveis [MINAYO, 2001].

Este trabalho descreve uma experiência em sala de aula de um curso livre de idiomas da cidade de Fortaleza (CE), na qual a professora, primeira autora deste artigo, no período de seis meses, utilizou atividades que envolvessem as quatro habilidades (compreensão oral e escrita; produção oral e escrita) no aplicativo Instagram

O aplicativo Instagram oferece diferentes ferramentas para interação com seus usuários. Dentre elas podemos citar postagens, curtidas, comentários, transmissões ao vivo e publicações em formato de história (stories). As histórias ou popularmente chamadas por seu nome em inglês stories são um meio de transmitir, por meio de vídeos ou imagens, elementos temporários que o usuário gostaria de compartilhar com seus contatos. O compartilhamento é temporário, por durar 24 horas, podendo ser guardado em um marcador criado pelo dono da conta, usuário que administra o perfil, caso este julgue seu story importante e ache que seus seguidores gostariam de visualizá-lo novamente.

As atividades consistiam em publicação de histórias com exercícios de compreensão oral (listening) de múltipla escolha, publicados semanalmente no aplicativo, além da publicação de vídeos no mural (feed de notícias). Durante o semestre foram compartilhadas 19 (quinze) histórias (stories) interativas e 25 (vinte e cinco) publicações no mural (feeds). O formato das publicações variava entre imagem com legenda explicativa bilíngue e vídeos com legendas que os rotulavam, convidando os usuários a os assistirem. Para as publicações no feed (mural) de notícias do Instagram, um limite de 56 segundos é permitido para mídias em vídeo. Devido ao tempo reduzido, 
VII Congresso Brasileiro de Informática na Educação (CBIE 2018)

Anais dos Workshops do VII Congresso Brasileiro de Informática na Educação (WCBIE 2018)

os textos a serem divulgados neste formato foram previamente planejados no intuito de serem objetivos, porém que atendessem seu propósito.

Pensou-se, então, em uma sintaxe padrão para vídeos, seguindo a seguinte ordem: saudação - com ou sem apresentação, uma vez que a apresentação pode ser realizada por meio de legenda na tela do próprio vídeo. Informações adicionais são válidas quando em pequenas quantidades, sem sobrecarregar quem assiste. A introdução é realizada em português. Isto ocorre para que haja o resgate do conhecimento prévio do aluno, pois acredita-se que o aprendiz já traz consigo algum conhecimento de mundo e aprende por associações. Ativar o conhecimento prévio facilitará o aprendizado [SHUBHADA,2016]. Para esta etapa, foram utilizadas perguntas como "você conhece...?", "você sabe..." ou "você sabia...?", na etapa que se seguiu, houve a apresentação do insumo, ou seja, do conteúdo com o qual pretendia-se trabalhar com o aluno.

O estudo foi realizado com 14 alunos do nível intermediário do curso de língua inglesa. O curso possui duração total de nove semestres, sendo os dois primeiros classificados em nível básico, o terceiro, pré-intermediário, os dois seguintes como níveis intermediários e os quatro últimos como níveis avançados.

Os participantes possuíam idades que variavam entre 14 a 50 anos. A escolha por alunos em nível intermediário deu-se pela diversidade lexical dos aprendizes e pela maturidade sintática que estes apresentavam, ao elaborarem sentenças mais complexas em seus discursos, expressando-se com mais fluidez na língua inglesa. Outro critério de escolha foi a possibilidade do uso ao aplicativo Instagram. Nesta turma, no nível B2 (semestre 4 do curso) todos os alunos possuíam conta no aplicativo e interagiam frequentemente.

Durante o período de aulas vigente, fez-se a coleta de dados da pesquisa. Dividido em duas etapas, cada uma composta por três meses, o semestre letivo do curso livre de língua demandou a realização de provas correspondentes ao final de cada uma das etapas concernentes às habilidades orais e escritas, sendo de obrigatoriedade, do curso, as provas de compreensão oral (listening), a prova escrita sobre o conhecimento gramatical do aluno (written test) e a prova oral (oral test), sendo esta última de livre elaboração do professor. A professora aplicou, também, prova de produção escrita (writing), a qual foi somada à prova de conhecimento gramatical equivalendo a uma questão extra.

No início do semestre, foi criado um grupo no aplicativo de troca de mensagens instantâneas Whatsapp. Um dos alunos sugeriu a criação do grupo para facilitar a comunicação entre os colegas. A professora pediu para fazer parte do grupo. Nas aulas, o perfil foi divulgado e os alunos seguiram, mas, nas primeiras semanas, a professora enviava notificou os alunos das atualizações no Instagram. As notificações ocorreram 3 (três) vezes, uma vez por semana, no mês de fevereiro. Após esse período, os alunos não mais foram notificados e passaram a acompanhar o perfil de forma independente.

Durante o semestre, 19 (quinze) histórias (stories) interativas foram publicadas e 25 (vinte e cinco) vídeos foram produzidos e publicados no mural. Nos primeiros dois meses, os alunos comentavam dos stories em sala de aula, mas, após este período, o acompanhamento da página pelos alunos ou a eficácia das atividades realizadas utilizando o aplicativo só pode ser verificada através do uso de vocábulos específicos utilizados pelos alunos em suas produções tanto orais quanto escritas. Os alunos que 
VII Congresso Brasileiro de Informática na Educação (CBIE 2018)

Anais dos Workshops do VII Congresso Brasileiro de Informática na Educação (WCBIE 2018)

resolveram as atividades gamificadas no Instagram, produziram discursos com grau de complexidade maior, dentro do nível B2. Este grau pode ser verificado a partir do uso de vocábulos específicos como conectivos ou uso de estratégias linguísticas para adequação de seus discursos.

As postagens eram realizadas de forma independente às aulas do curso, mas os conteúdos estavam conectados, sempre fazendo parte do que estava sendo visto. Houve o cuidado para que o aplicativo não se transformasse em uma extensão da sala de aula, mas uma forma de oferecer mais insumo para a produção livre dos alunos e maior imersão na língua e cultura inglesa.

\section{Resultados e Discussão}

As publicações realizadas no perfil que a professora criou para apoiar os processos de ensino aprendizagem eram baseadas nas atividades realizadas em sala. Isto foi planejado para que os alunos pudessem ser desafiados e motivados a buscar respostas aos desafios propostos pela professora. $\mathrm{O}$ intuito era que as postagens ajudassem os alunos a se aproximar dos conteúdos que eram vistos em sala de aula, como podemos ver na figura 01.

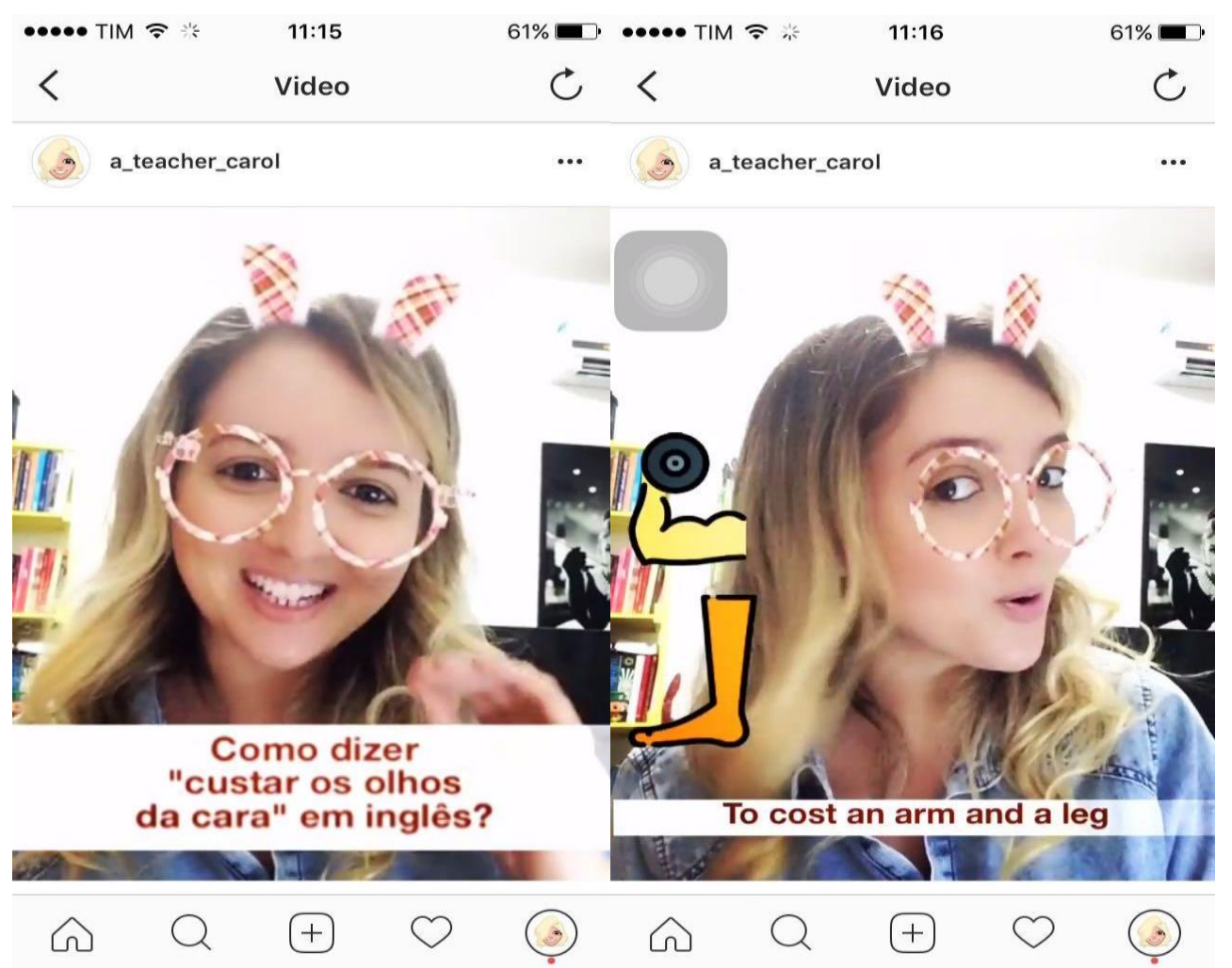

Figura 1. Captura de tela do vídeo 'Como dizer "custar os olhos da cara" em inglês?'

Os vídeos foram utilizados para muitos fins, desde o trabalho com vocabulário (como dizer as horas em inglês, expressões) até pronúncia e articulação dos constituintes do sistema fonador. Nesta etapa, o insumo passa a ser ofertado na língua- 
VII Congresso Brasileiro de Informática na Educação (CBIE 2018)

Anais dos Workshops do VII Congresso Brasileiro de Informática na Educação (WCBIE 2018)

alvo (inglês), tornando-se mais fácil seu aprendizado e compreensão, pois o aluno já fez conexões com o que conhecia previamente através da etapa anterior.

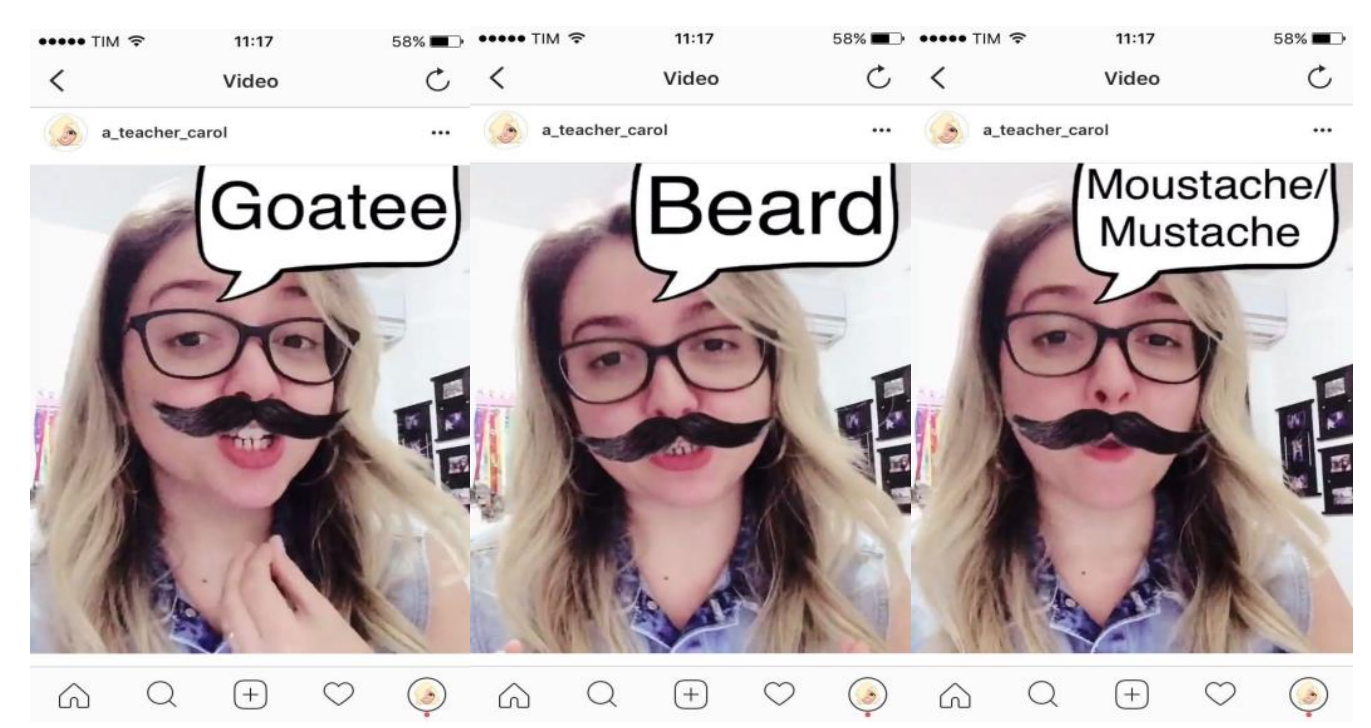

Figura 2. Captura de tela do vídeo "Barba, cabelo e bigode".

Na penúltima etapa, há a repetição da forma ofertada no insumo. A repetição pode ser feita um pouco mais lentamente. Para finalizar, após a fase de repetição, há uma conclusão (caso haja tempo) com o retorno ao questionamento inicial ou apenas uma despedida (caso não haja mais tempo). No caso de expressões e pronúncia de palavras, 56 segundos é um tempo executável. Para conteúdos mais complexos, houve a gravação de até três vídeos. Pontua-se, portanto, a importância de não perder o pace (ritmo) pois o aplicativo demanda grande imediatismo por parte de seus usuários. Isto o difere de outras ferramentas, fazendo com que os alunos optem pelo uso do Instagram como uma extensão de sala de aula. A figura abaixo ilustra uma sugestão de um padrão de sintaxe, elaborada para a criação de vídeos no perfil @a_teacher_carol no aplicativo:

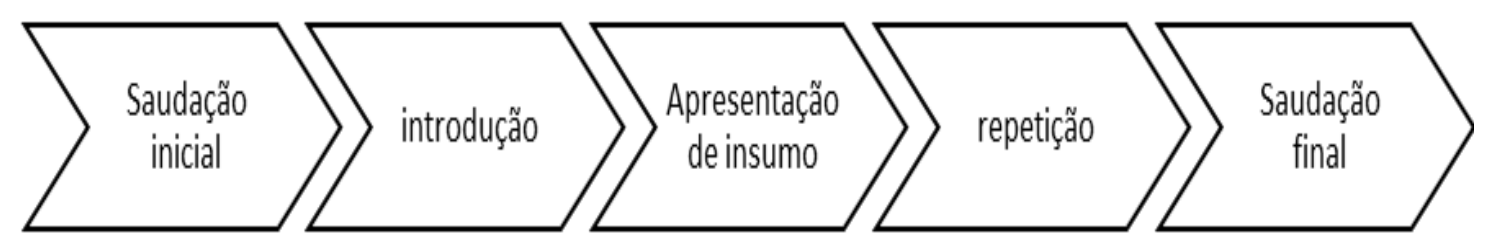

Figura 3: Etapas da sintaxe para criação de vídeos educacionais no Instagram. Fonte própria.

A criação de uma sintaxe para a elaboração de vídeos no Instagram foi importante para padronizar o ambiente e não fugir do foco do próprio vídeo, atingindo os objetivos traçados previamente. Dentro desta dinâmica, criada a partir da própria observação dos primeiros vídeos e seu aperfeiçoamento, foi possível pensar, de forma mais objetiva, nos conteúdos a serem trabalhados e nos textos a serem escritos, de forma que o insumo fosse apresentado de maneira clara e direta, respeitando o tempo limite para a postagem de vídeos no feed (mural) de notícias do aplicativo. 
VII Congresso Brasileiro de Informática na Educação (CBIE 2018)

Anais dos Workshops do VII Congresso Brasileiro de Informática na Educação (WCBIE 2018)

A figura 4 (quatro) exemplifica uma sequência de publicações de uma atividade de compreensão oral (listening) já utilizada tradicionalmente em sala de aula, adaptada para o aplicativo Instagram. Para esta atividade, foi utilizada a canção Million Reasons, da cantora norte-americana Lady Gaga. A atividade consistia em ouvir a canção e completar as lacunas com as palavras correspondentes. Duas opções foram dadas através da ferramenta poll (enquete), disponível nos stories do aplicativo.

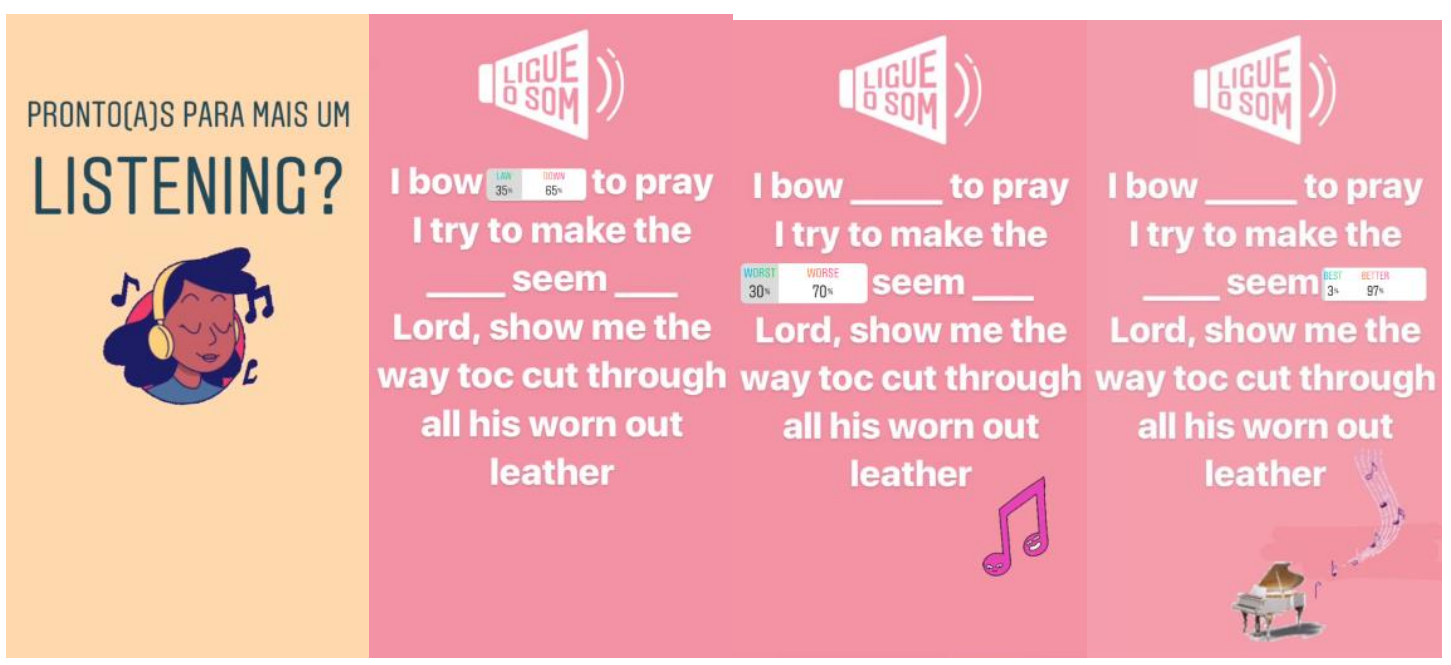

Figura 4: Captura da tela dos stories do perfil @a_teacher_carol com a atividade de Listening.

Os seguidores, grupo constituído por alunos, ex-alunos, professores e demais interessados na língua, responderam à enquete. Das 30 respostas, 10 foram dos alunos de nível intermediário (B2lers ${ }^{2}$ ), 14 foram ex-alunos de níveis diversos e 6 foram de seguidores interessados na língua. Os alunos, na aula seguinte, comentaram a atividade postada no Instagram com a professora e com seus colegas, pedindo para que o vocabulário utilizado na canção fosse revisado na aula e incluído aos exemplos do conteúdo gramatical o qual estava sendo trabalhado presencialmente.

A atividade no aplicativo favoreceu uma extensão da sala de aula em que esta confunde-se com o próprio ambiente educacional, pois os alunos despertam a curiosidade em aprender mais sobre a língua. Esse tipo de motivação, partindo do próprio aluno, faz com que sua aprendizagem seja significativa, fazendo com que sua casa, um ambiente não-formal de aprendizagem, seja perfeitamente aplicável para uma atividade de compreensão auditiva em LE, por exemplo. Para Pivelli [2006], diferente da educação informal, que engloba todas as formas de aprendizagem que o indivíduo possui durante a vida, a educação em contexto não-formal é aquela que vai além do ambiente da sala de aula, mas que se propõe a ensinar o que o currículo escolar contém, ensinando fora da sala de aula. Ensinar utilizando um aplicativo como o Instagram, por exemplo, proporciona um ensino em um ambiente não-formal, com uma roupagem informal, já que decorre de processos espontâneos.

\footnotetext{
${ }^{2}$ De acordo com o quadro europeu comum de referência para línguas (common European framework of reference for languages- CEFR), o nível B2 é o quarto nível, chamado de "intermediário superior" (upper intermediate). Chamamos de B2lers os aprendizes desse nível, pois são "B2 learners".
} 
VII Congresso Brasileiro de Informática na Educação (CBIE 2018)

Anais dos Workshops do VII Congresso Brasileiro de Informática na Educação (WCBIE 2018)

A educação informal abrange todas as possibilidades educativas proporcionadas ao longo da vida de um indivíduo, constituindo um processo permanente e não-organizado. Pode ser transmitida pelos pais na família, no convívio com os amigos, clubes, teatros, leituras de jornais, livros, revistas e mídia. Ela decorre de processos espontâneos ou naturais, ainda que seja carregada de valores ou representações. [PIVELLI, 2006, p.74]

As enquetes foram utilizadas para outras atividades como listening (atividades de compreensão oral) de outras canções ou enigmas lançados pela professora, que só eram revelados posteriormente. Grande parte das interações foi realizada utilizando o recurso story (história) do aplicativo. Isto comprova o potencial pedagógico com [PIVELLI, 2006] do aplicativo Instagram, que pode ter um ou mais de seus recursos utilizados para fins educacionais, proporcionando aprendizagem de conteúdos em contextos informais de ensino.

As atividades e comentários realizados no perfil do Instagram mostraram a incorporação do vocabulário trabalhado nas atividades de listening nas histórias do aplicativo Instagram. Os alunos que responderam às enquetes e participaram das atividades, respondendo às perguntas, incorporaram ao seu léxico novos vocábulos que não estavam programados dentro do currículo da escola de idiomas.

Houve ganhos não somente da aquisição lexical, mas no que concerne à produção oral dos alunos. Ao ganharem mais vocabulário e permitirem maior acesso lexical, os alunos que participaram das atividades interativas utilizando o aplicativo Instagram, produziram melhores discursos, com maior fluidez e menos pausas. Menos falhas na pronúncia foram observadas em suas últimas avaliações orais, comparando com alunos que não participaram das atividades.

Isto foi verificado nas produções, em que, os alunos que haviam interagido nas atividades de listening, apresentaram ganho vocabular, incluindo novas palavras e diferentes conectores (however; since; once; but- no sentido de "com exceção de") tanto em suas produções escritas, quanto em suas produções orais. Em sala de aula, as palavras utilizadas nas atividades ofertadas nas histórias (stories) do Instagram, foram incorporadas ao discurso nos chamados role plays, nos quais os alunos deveriam criar situações reais das esferas de comunicação humana e interpretar papeis diversos. Os alunos que participavam e interagiam com as atividades propostas no aplicativo, apresentaram maior diversidade lexical, indo além do vocabulário sugerido no livrotexto.

\section{Conclusões}

Este trabalho teve por objetivo descrever uma das experiências de uso do software aplicativo Instagram por uma professora de um curso livre de idiomas, apresentando atividades realizadas com alunos, professores e comunidade interessada. Os resultados apresentaram ganhos reais para os alunos, refletidos em suas habilidades orais, ao produzirem discursos e demonstrarem estruturas mais complexas e ricas após maior aquisição de vocabulário. 
O aplicativo Instagram pode ser utilizado como ferramenta educacional, desde que as atividades sejam pensadas para explorar a funcionalidade do aplicativo. É necessário pensar nos ganhos de aprendizagem, no caso da aprendizagem de uma LE, na aquisição de vocabulário, na acurácia na compreensão de formas orais etc., que o aluno terá ao utilizar a ferramenta em um contexto não-formal de ensino [GOHN, 1999].

Os resultados ressaltam o uso de formas criativas dos instrumentos existentes dentro do aplicativo, que são, em geral, voltados para a comunicação. Como o ensino da língua concerne seus usos e aplicações comunicativas, pensando nas relações interpessoais, o Instagram agrega diferentes esferas da sociedade humana, trabalhando diferentes discursos e seus gêneros. Cabe ao professor refletir o potencial pedagógico de uso do software para que a aprendizagem da língua se dê em um contexto não-formal de ensino.

\section{Referências}

Aristovnik, A. The impact of ICT on educational performance and its efficiency in selected EU and OECD countries: A non-parametric analysis. Turkish Online Journal of Educational Technology, v. 11, n. 3, p. 144-152, 2012.

Blikstein, p.(2013) Digital fabrication and 'making'in education: The democratization of invention. FabLabs: Of machines, makers and inventors", p. 1-21, 2013.

Brito, André Luiz de Souza; Madeira, Charles Andryê Galvão (2017). Metodologias Gamificadas para a Educação: um revisão sistemática. In Brazilian Symposium on Computers in Education (Simpósio Brasileiro de Informática na Educação-SBIE), volume 27, page 133

Dewey, J. (2001). Democracy and Education. Hazleton: The Pennsylvania State University - Electronic Classics Series

.(2010) Experiência e educação: textos fundantes de educação. Petrópolis: Vozes.

Gohn, M.D.G.(1999) Educação não-formal e cultura política. São Paulo:Cortez,.

Hartnett, M., St George, A., and Dron, J. (2014). Exploring motivation in an online context: A case study. Contemporary Issues in Technology and Teacher Education, 14(1):31-53.

Kattimani, S. F; Naik, R.R. E-learning technology in the ICT era: application to technical education. DESIDOC Journal of Library \& Information Technology, v. 32, n. 6, nov., p. 459-467, 2012.

Minayo, M. C. S. (Org.). (2001) Pesquisa social: teoria, método e criatividade. Petrópolis: Vozes.

Papert, Seymour. (1991). Situating Constructionism. In I. Harel e S. Papert (Ed.), Constructionism (pp. 1-12). Norwood, NJ: Ablex Publishing. . (2007) A máquina das crianças: repensando a escola na era da informática. ed. rev. Porto Alegre: Artmed. .(1986) Logo: computadores e educação. São Paulo: Brasiliense, 1986 
VII Congresso Brasileiro de Informática na Educação (CBIE 2018)

Anais dos Workshops do VII Congresso Brasileiro de Informática na Educação (WCBIE 2018)

sua conservação. Dissertação (Mestrado em Educação). Programa de Pós-Graduação em Educação da Universidade de São Paulo,São Paulo. Disponível em: <http://www.teses.usp.br/teses/disponiveis/48/48134/tde-22062007-092500/ptbr.php>. Acesso em: 01 Jul. 2018.

Raabe, André Luís Alice et al. (2016). Lite Maker: Uma estação móvel que possibilita transformar a sala de aula em espaço maker. In Anais da 1a. Conferência FabLearn Brasil 2016. Disponível em http://fablearn.org/wpcontent/uploads/2016/09/FLBrazil_2016_paper_149.pdf acesso em 14 de Junho de 2018.

Rubio, M; Romero, L. Apostar Por La Calidad De La Educación Superior A Distancia Desde La Pertinencia Social. RIED, v. 8, n. 1-2, p 159-192, 2005.

Sarmento, M.; Miranda, A.; Baptista, A.; Ramos, I. Algumas considerações sobre as principais declarações que suportam o movimento Acesso Livre. In: World Congress on Health Information and Libraries. Salvador, Bahia, Brasil, 20-23 Set. 2005

Shubhada K. Deshpande (2016). Activating Background Knowledge: An Effective Strategy to Develop Reading Comprehension Skills. In Journal of English Language Teaching and Linguistics (JELTL) Vol. 1 (3), p.191

Smith, Mark.(1996) Curriculum Theory and Practice, 1996. [online]. Disponível para download em http://www.infed.org/biblio/b-curric.htm. e consultada em 01 de julho de 2018.

Simsom, O.R.D.M.V; Park, M.B; Fernandes,RS.(2001) Educação não-formal: cenários da criação.Campinas:Unicamp.

Thiollent, M. (1999). Notas para o debate sobre pesquisa-ação. In C. R. Brandão (Org.), Repensando a pesquisa participante (pp. 82-103). São Paulo: Brasiliense. 